\title{
Role of Cervical Length as Predictor of Preterm Labor and a Comparison of Transabdominal versus Transvaginal Ultrasound in Determining the Accuracy of Cervical Length
}

\author{
${ }^{1}$ PD Lakhani, ${ }^{2}$ AS Bansode, ${ }^{3}$ MS Nanavati, ${ }^{4}$ SV Desai \\ ${ }^{1}$ Lecturer, Nowrosjee Wadia Maternity Hospital, Parel, Mumbai, Maharashtra, India \\ ${ }^{2}$ Registrar, Nowrosjee Wadia Maternity Hospital, Parel, Mumbai, Maharashtra, India \\ ${ }^{3}$ Honorable Associate Professor and Unit Head, Nowrosjee Wadia Maternity Hospital, Parel, Mumbai, Maharashtra, India \\ ${ }^{4}$ Honorable Associate Professor, Nowrosjee Wadia Maternity Hospital, Parel, Mumbai, Maharashtra, India
}

Correspondence: PD Lakhani, Lecturer, Nowrosjee Wadia Maternity Hospital, Parel, Mumbai, Maharashtra, India e-mail: payal_lakhani@rediffmail.com

\begin{abstract}
Objectives: 1. To evaluate the mean cervical length at 22 to 28 weeks of gestation by TAS and TVS and correlate its association with preterm labor.

2. To compare the difference in cervical length measured by the above two methods.

Methods: This was a prospective trial involving 100 pregnant women spanning a period of ten months.

Results: Eighteen women out of the 100 studied had preterm labor; of which 17 had a cervical length of less than $3 \mathrm{~mm}$ at 22 to 28 weeks. The percentage of women with preterm delivery with a short cervix was $83 \%$ by transabdominal scan (TAS) and $94 \%$ with transvaginal scan (TVS).

Conclusion: The mean cervical length was lesser amongst women who had a preterm delivery as compared to those with a term delivery. The mean cervical length by TAS was more than that by TVS thereby suggesting that TVS has a higher sensitivity for detection of preterm labor than TAS.

Keywords: Cervical length, preterm labor, transabdominal, transvaginal sonography.
\end{abstract}

\section{INTRODUCTION}

Preterm birth; which is one of the major challenges faced by obstetricians world over is defined as childbirth occurring at less than 37 completed weeks or 259 days of gestation.

Apart from being a risk factor for perinatal morbidity and mortality; it is known to lead to long-term adverse development outcomes like cerebral palsy, retinopathy, learning disabilities, etc. This in turn puts an additional economic burden on a developing country like ours.

Global incidence of preterm labor is approximately $9.6 \%$ of all births. ${ }^{1}$ Various Indian studies show the incidence to be between 11 and $14 \%$.

It is known that cervix plays a pivotal role in preterm delivery; hence, identification of women likely to have a preterm birth would require a simple ultrasonographical measurement of the cervical length. ${ }^{2}$

Ultrasonography is now routinely used for pregnancy dating, screening for anomalies and monitoring fetal growth.

We planned this study to identify the optimal method of USG for the assessment of cervical length in the late second trimester and to compare TAS and TVS route for screening for spontaneous preterm delivery.

\section{METHODS}

This prospective trial spans ten months and includes 100 pregnant women in a tertiary care center and postgraduate teaching institute. The subjects were recruited in the late second trimester as they came for routine antenatal follow-up. Their gestational age was confirmed from their menstrual history and first trimester scan. The inclusion criteria was a singleton live pregnancy regardless of parity and obstetric history. The exclusion criteria were-history of bleeding in first trimester, presence of uterine fibroid, PIH, GDM, low lying placenta and women who had already undergone a cervical encirclage in this pregnancy.

Transabdominal USG was performed using a Wipro Logic machine. A 3.5 MHz probe was used to measure the cervical length with a full bladder. The cervix was viewed as an echogenic line extending from the internal to external os. Measurements were taken twice in a sagittal plane and a mean of the two was taken.

Transvaginal sonography was performed on an empty bladder. The patient was put in a dorsal lithotomy position and a $5 \mathrm{MHz}$ endovaginal probe covered with a sterile condom was inserted in the vagina until an adequate sagittal image of the 
cervix was visualized. The probe was then slightly withdrawn till the image blurred and then insertion pressure was increased only enough to restore an adequate image. The external os was identified by its triangular echodensity and internal os by its V shaped appearance. The distance between the two was taken as cervical length. Measurements were taken twice and a mean of the two was taken.

The same USG machine was used for TVS and TAS and the scans were performed by the same researcher to avoid interpersonal error.

All women were followed throughout the course of gestation till delivery and the data was then corroborated.

\section{RESULTS}

The incidence of preterm delivery was $22 \%$ in our trial $78 \%$ of patients delivered after 37 completed weeks of gestation.

A frequency distribution of the cervical lengths in the two groups is shown below:

Mean cervical length in term and preterm patients

\begin{tabular}{lccc} 
& \multicolumn{3}{c}{ Mean cervical length $(\mathrm{cm})$} \\
Period of gestation & TAS & TVS & Total no. of patients \\
Term & $3.3 \mathrm{~cm}$ & $3.1 \mathrm{~cm}$ & 78 \\
Preterm & $2.8 \mathrm{~cm}$ & $2.5 \mathrm{~cm}$ & 22
\end{tabular}

The mean gestational age at the time of ultrasound measurement of the cervix was 25 weeks and the mean gestational age at birth was 37.4 weeks.

It was observed that the mean cervical length among patients with term delivery is more than those with preterm labor and this difference is statistically significant. The observation is consistent with both TVS and TAS.

Distribution of cervical length on TVS and TAS

$\begin{array}{lrr}\text { Cervical length (mm) } & \begin{array}{c}\text { No. of patients } \\ \text { (TAS) }\end{array} & \begin{array}{c}\text { No. of patients } \\ \text { (TVS) }\end{array} \\ 2 \mathrm{~mm} & 1 & 3 \\ 2-2.5 \mathrm{~mm} & 5 & 10 \\ 2.6-3 \mathrm{~mm} & 30 & 45 \\ 3.1-3.5 \mathrm{~mm} & 28 & 23 \\ 3.6-4 \mathrm{~mm} & 22 & 10 \\ >4 \mathrm{~mm} & 14 & 9\end{array}$

Comparison of mean cervical length measurement by TAS and TVS shows that mean cervical length measured by TAS is $3.05 \mathrm{~mm}$ and that measured by TVS is $2.8 \mathrm{~mm}$. This difference is statistically significant.

Detection of preterm labor by TAS at $3.2 \mathrm{~mm}$ cut off (50\%)

$\begin{array}{lccc}\text { Cervical length } & \text { Preterm } & \text { Term } & \text { Total } \\ \leq 3.2 \mathrm{~mm} & 15 & 38 & 53 \\ >3.2 \mathrm{~mm} & 3 & 44 & 47\end{array}$

Detection of preterm labor by TVS at $3 \mathrm{~mm}$ cut off (50\%)

$\begin{array}{lccc}\text { Cervical length } & \text { Preterm } & \text { Term } & \text { Total } \\ \leq 3 \mathrm{~mm} & 17 & 41 & 58 \\ >3 \mathrm{~mm} & 1 & 41 & 42\end{array}$

\section{DISCUSSION}

Preterm birth is a major cause of perinatal morbidity and mortality. Prediction of preterm delivery by simple techniques will help in early intervention and subsequent prevention of preterm labor. This is especially important in a country like ours where intensive care facilities are often not available or may be financially not feasible.

Various trials have been carried out to predict preterm labor using different criteria. Fetal fibronectin which is normally present in cervicovaginal secretions before 22 weeks and after 37 weeks of gestation has been measured in earlier studies. If the amount of fetal fibronectin in the secretions is more than 50 $\mathrm{ng} / \mathrm{ml}$ it suggests that the woman is at a high risk of preterm delivery. However, these studies need to be repeated in a low risk and high risk population alike if it has to be used as a diagnostic modality.,4 This involves a huge cost and an additional load on the pathologist.

Uterine activity monitoring has provided a positive predictive value of $25 \%$ in certain studies, ${ }^{5,6}$ but it is a subjective test based on the patient's perception. Daily telephonic contact with health care providers has also proved to be effective as claimed by Sacks BP et al. ${ }^{5}$

Ultrasonographic assessment of the cervix has always been considered as a safe, easy and effective method to predict preterm labor.

Previous studies ${ }^{7}$ have shown that when measured by the TAS method the cervical length increases with increasing bladder volume especially if bladder is over distended. There is an apparent linear cervical lengthening with increasing bladder volume. Also, partial compression of the lower uterine segment gives an impression of a partially dilated endocervical canal and even funneling; thus, misleading us to diagnose it as a short cervix which warrants further management.

A study was conducted by Lisa et $\mathrm{al}^{8}$ to evaluate whether a post void TAS is a reliable method for cervical length assessment. They found that with optimal sonographic techniques, post void TAS cervical length shows a close correlation with TVS method. However, an empty bladder makes it difficult to optimally visualize the cervix. Earlier studies have also compared a USG guided cervical length versus a digital assessment of the cervix $;{ }^{9,10}$ however, a digital examination is a subjective method and is unable to detect the supravaginal portion of the cervix. After studying the past literature we decided to use a USG guided method to measure cervical length in our study.

It is essential for sonologists today, to become familiar with methods of cervical imaging like TAS/TVS ${ }^{11,12}$ and translabial sonography.

It is observed in the present study that the sensitivity and specificity values for the 50th percentile cut offs are $90 \%, 55.3 \%$ respectively for TAS and 95\%, 48.94\% respectively for TVS. ${ }^{14,15}$ Both TVS and TAS have a high sensitivity value and can be used as a screening tool for prediction of preterm labor but a TVS has a high negative predictive value as well which rules

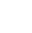


out the possibility of unnecessary interventions of unproven value such as tocolysis, hospitalization and bedrest.

\section{CONCLUSION}

There is a very strong correlation between a short cervix and preterm labor.

Transvaginal sonography is a safe, acceptable and sensitive method to predict preterm labor and scores over a transabdominal sonography in terms of specificity and negative predictive value. ${ }^{13}$

\section{REFERENCES}

1. Creasy RK. Preterm birth prevention: Where are we? Am J Obstet Gynecol 1993;168:1223-30.

2. Leung TN, Pang MW, et al. Cervical length at 18-22 weeks of gestation for prediction of spontaneous preterm delivery in Hong Kong Chinese women. ISUOG 2005 (Prince of Wales Hospital Hong Kong).

3. Goldenberg RL, Iams JD, Das A, et al. The preterm prediction study: Sequential cervical length and fetal fibronectin testing for prediction of spontaneous preterm birth. Am J Obstet Gynecol 2000;182:636-43.

4. Faron G, Boulvain M, Inon O, et al. Prediction of preterm delivery by fetal fibronectin: A meta analysis. Obstet Gynecol 1998;92:153-58.

5. Sacks BP, Heller Stein S, Freeman R, et al. Home monitoring of uterine activity-does it prevent prematurity? N Engl J Med 1991;325:1374-77.

6. Main D, Katz M, Chieu G, et al. Intermittent weekly contraction monitoring to predict preterm labor in low risk women. Obstet Gynecol 1988;72:757-61.
7. Mason GC, Maresh MJ. Alteration bladder volume and the ultrasound appearance of the cervix. BJOG May 1990;97(5): 457-58.

8. Lisa L, Saul MD, James T Kurtzman, et al. Is transabdominal sonography of the cervix after voiding a reliable method of cervical length assessment? J Ultrasound Med 2008;27:1305-11.

9. Gomez R, Galasso M, Romero R, et al. Ultrasonographic examination of uterine cervix is better than cervical digital examination as a predictor of likelihood of premature delivery in patients with preterm labor and intact membranes. Am J Obstet Gynecol 1994;171:956-64.

10. Sonek JD, Iams JD, Blumenfeld M, et al. Measurement of cervical length in pregnancy. Comparison between vaginal ultrasonography and digital examination. Obstet Gynecol 1990;76:172-75.

11. H Frank Anderson. Transvaginal sonography and transabdominal sonography of uterine cervix during pregnancy. J Clinical Ultrasound Dec 2005;19(2):77-83.

12. Honest H, Bachmann LM, Coomarasamy A. Accuracy of cervical transvaginal sonography in predicting preterm births. A systematic review. Ultrasound Obstet Gynecol Sep 2003;22(3):305-22.

13. Anderson HF, Nugent CE, Wanty SD, Hayashi RH. Prediction of risk of preterm delivery by ultrasonographic measurement of cervical length. Am J Obstet Gynecol 1990;163:859-67.

14. Bega G, Lev Toaff A, Kahlman K, et al. Three-dimensional multiplanar TVS of cervix in pregnancy. Ultrasound Obstet Gynecol 2000;16:351-58.

15. Kore SJ, Parikh MP, Lakhotia S, et al. Prediction of risk of preterm delivery by cervical assessment by transvaginal sonography. J Obstet Gynecol India. Mar/Apr 2009;59(2): 131-35. 